\title{
TDGF1 is a novel predictive marker for metachronous metastasis of colorectal cancer
}

\author{
NORIKATSU MIYOSHI ${ }^{1}$, HIDESHI ISHII ${ }^{1,2}$, KOSHI MIMORI ${ }^{2}$, \\ MITSUGU SEKIMOTO $^{1}$, YUICHIRO DOKI ${ }^{1}$ and MASAKI MORI ${ }^{1}$

\begin{abstract}
${ }^{1}$ Department of Gastroenterological Surgery, Osaka University Graduate School of Medicine, Suita, Yamadaoka 2-2, Osaka 565-0871; ${ }^{2}$ Department of Molecular and Cellular Biology, Division of Molecular and Surgical Oncology,
\end{abstract} \\ Kyushu University, Medical Institute of Bioregulation, Tsurumihara 4546, Beppu, Ohita 874-0838, Japan
}

Received September 30, 2009; Accepted November 16, 2009

DOI: 10.3892/ijo_00000530

\begin{abstract}
Teratocarcinoma-derived growth factor 1 (TDGF1) is a member of the epidermal growth factor-cripto FRLI cryptic protein family and is involved in the activation of several different signaling pathways during embryonic development and cellular transformation. Previous reports show that TDGF1 regulates the activation of several signaling pathways and controls cellular transformation in embryonic status, whereas its significance in colorectal cancer (CRC) is not yet fully understood. The present study comprised 55 patients who underwent surgery for CRC, as well as two cell lines derived from human CRC. The correlation of gene expression with clinical parameters in patients was assessed. The biological significance of TDGF1 expression was evaluated by knockdown experiments in the cell lines. Seventeen of 55 (30.9\%) cases exhibited a higher TDGF1 expression in cancerous regions than in marginal non-cancerous regions. Patients with high $T D G F 1$ expression were statistically susceptible to a recurrence of the disease, and showed poorer disease-free survival than those with low expression. The assessment of TDGF1 knock-down in the 2 cell lines demonstrated that the siRNA inhibition resulted in a statistically significant reduction in cell growth and invasion. In conclusion, the present data strongly suggest the usefulness of TDGF1 as a predictive marker for metachronous metastasis in CRC patients.
\end{abstract}

\section{Introduction}

Cancer is a prominent malignancy in many developed countries, including the United States and Japan $(1,2)$. The incidence of colorectal cancer (CRC) has increased significantly in recent years in concert with the changing lifestyle (3). The major cause of death from CRC is liver

Correspondence to: Dr Masaki Mori, Department of Gastroenterological Surgery, Osaka University, Yamadaoka, Suita 2-2, Osaka 565-0871, Japan

E-mail: mmori@gesurg.med.osaka-u.ac.jp

Key words: teratocarcinoma-derived growth factor 1, metastasis, colorectal cancer metastases (4). Although treatment has recently improved, it fails in approximately one-third of patients, who require an alternative strategy (2). Thus, useful predictive markers are needed for CRC patients.

Tumor-promoting oncogenes and tumor suppressors control cell proliferation through CRC cell cycle arrest $(1,5,6)$. Identifying additional genes responsible for the development and progression of $\mathrm{CRC}$, as well as understanding their clinical significance would improve diagnosis and treatment of the disease. The characterization of key molecules is particularly promising for the development of novel approaches to treat gastrointestinal tumors.

The human teratocarcinoma-derived growth factor 1 (TDGF1) gene is a member of the epidermal growth factorcripto FRL1 cryptic gene family and was initially isolated from human teratocarcinoma (7). TDGF1 is expressed in several types of human tumors and has been detected by immunohistochemistry in the breast, stomach, colon, pancreas, and lung (8-16). For gastric cancer, the combined expression of TDGF1 and E-cadherin is reported as a prognostic factor (16).

We investigated the importance of the TDGF 1 gene by analyzing it in 55 consecutive paired cases of CRC and noncancerous regions as well as in $2 \mathrm{CRC}$ cell lines. We propose that $T D G F 1$ expression is important for prognostic evaluation and suggest that TDGF1 could be a novel marker for CRC prognosis.

\section{Materials and methods}

Clinical tissue samples. The study comprised 55 consecutive patients who underwent surgery for CRC at Osaka University from 2003 to 2004. Primary CRC specimens and adjacent normal colorectal mucosa were obtained from patients after written, informed consent was confirmed in accordance with the institutional ethics guidelines. The surgical specimens were fixed in formalin, processed through graded ethanol, embedded in paraffin, and sectioned with hematoxylin and eosin. All specimens were frozen immediately in liquid nitrogen after resection and kept at $-80^{\circ} \mathrm{C}$ until RNA extractions. After surgery, patients were followed up with a blood examination including the tumor markers serum carcinoembryonic antigen (CEA) and cancer antigen (CA19-9), as well as imaging modalities, such as abdominal ultrasonography, computed 
tomography, and chest X-ray every 3-6 months. Clinicopathological factors were assessed according to the tumornode-metastasis (TNM) criteria classification of the International Union Against Cancer (UICC) (17).

Cell lines and culture. Two cell lines derived from human CRC, HCT116 and LoVo, were used in this study $(18,19)$. They were maintained in Dulbecco's minimal essential medium containing $10 \%$ fetal bovine serum and antibiotics at $37^{\circ} \mathrm{C}$ in a $5 \%$ humidified $\mathrm{CO}_{2}$ atmosphere. For siRNA inhibition, double-stranded RNA duplexes targeting human TDGF 1, (5'-AAGACUUUAGAAAUGGCCAUGAUCC-3' 5'-GGAUCAUGGCCAUUUCUAAAGUCUU-3', 5'-UUUA CUGGUCAUGAAAUUUGCAUGA-3'/5'-UCAUGCAAAU UUCAUGACCAGUAAA-3', and 5'-UGGACGAGCAAAU UCCUGAUGGCCC-3'/5'-GGGCCAUCAGGAAUUUGCU CGUCCA-3'), as well as negative control siRNA (NC) were purchased in the Stealth RNAi kit (Invitrogen, Carlsbad, CA, USA). CRC cell lines were transfected with siRNA at a concentration of $20 \mu \mathrm{mol} / \mathrm{l}$ using lipofectamine RNAiMAX (Invitrogen), incubated in glucose-free Opti-MEM (Invitrogen), treated in accordance with the manufacturer's protocols, and analyzed by proliferation assay. All siRNA duplexes were used together as a triple transfection. The number of cell cultures was measured by counting cells with a CellTac kit (Nihon Koden, Tokyo, Japan). siRNA knockdowns were performed in the two CRC cell lines to evaluate proliferation and invasion under TDGF1 suppression. Each cell line with siRNA was compared to the wild-type and a negative control. Values were expressed as the mean \pm standard error of mean (SEM) from five independent experiments.

$R N A$ preparation and quantitative real-time reverse transcriptase-polymerase chain reaction ( $R T-P C R)$. Total RNA was prepared using TRIzol reagent and a PureLink RNA Mini kit (Invitrogen) in accordance with the manufacturer's protocols. RNA was reverse transcribed with SuperScriptIII (Invitrogen), and a 119-bp TDGF1 fragment was amplified. Two human TDGF 1 oligonucleotide primers for the PCR reaction were designed as follows: 5'-AGATGGCCCGCTTCTCTTAC-3' (forward), 5'-CAGGTATCCCCGAGATGGAC-3' (reverse). The forward primer is located in exon 1 and the reverse primer is located in exon 2. PCR was performed with primers specific to the glyceraladehyde-3-phosphate dehydrogenase (GAPDH) gene. The GAPDH primers 5'-TTGGTATCGTGGAAGGAC TCA-3' (forward) and 5'-TGTCATCATATTGGCAGGTT-3' (reverse) produced a 270-bp amplicon. cDNA from the human reference total RNA (Clontech, Palo Alto, CA, USA) was used as a source of positive controls. Real-time PCR monitoring was performed using the Light Cycler FastStart DNA Master SYBR-Green I kit (Roche Diagnostics, Tokyo, Japan) for $T D G F 1$ and GAPDH cDNA amplification. The amplification protocol consisted of 35 cycles of denaturation at $95^{\circ} \mathrm{C}$ for 10 sec, annealing at $60^{\circ} \mathrm{C}$ for $10 \mathrm{sec}$, and elongation at $72^{\circ} \mathrm{C}$ for $10 \mathrm{sec}$. The products were then subjected to a temperature gradient from 55 to $95^{\circ} \mathrm{C}$ at $0.1^{\circ} \mathrm{C} \mathrm{s}^{-1}$ with continuous fluorescence monitoring to produce product melting curves. The expression ratio of mRNA copies in tumor and normal tissues was calculated and normalized against GAPDH mRNA expression.
Proliferation and invasion assays. To assess the cell proliferation after $48 \mathrm{~h}$ of siRNA transfection, they were grown for another $48 \mathrm{~h}$. The cell viability was determined utilizing Cell Counting kit consisted of WST-8 (Dojin, Tokyo, Japan). WST-8 $(10 \mu \mathrm{l})$ was added to the $100 \mu \mathrm{l}$ medium containing each supplement above, and the absorbance was read at $450 \mathrm{~nm}$ using Microplate Reader (Model 680XR, Bio-Rad Laboratories, CA). All the experiments were performed at $50-80 \%$ cell confluence, and the results were confirmed in five independent experiments. The values were expressed as a ratio/control (every parental cell).

Cell invasion were assessed with CytoSelect Cell Invasion Assay according to the protocol of the manufacture (Cell Biolabs, San Diego, CA) after $48 \mathrm{~h}$ of the transfection. Cells $\left(1.0 \times 10^{5}\right)$ in DMEM were placed on each $8.0-\mu \mathrm{m}$ pore size membrane insert in 96-well plates. DMEM with $10 \%$ FBS was placed in the bottom wells. After $24 \mathrm{~h}$, cells that did not invade were removed from the top side of the membrane chamber and completely dislodge the cells from the underside of the membrane by tilting the membrane chamber in the Cell Detachment Solution (Cell Biolabs). Lysis Buffer/CyQuant GR dye solution (Cell Biolabs) were added to each well, the fluorescence of the mixture was read with a fluorescence plate reader at $480 / 520 \mathrm{~nm}$. The values were expressed as a ratio/ control (every parental cell).

Statistical analysis. The variable data are expressed as mean \pm SEM. The relationship between TDGF 1 expression and clinicopathological factors was analyzed with the $\chi^{2}$ test. KaplanMeier survival curves were plotted and compared with the generalized log-rank test. Univariate and multivariate analyses were performed to identify prognostic factors using a Cox proportional hazard regression model. The Wilcoxon rank test was used to compare differences in TDGF 1 siRNA among the cell lines. All tests were analyzed with JMP software (SAS Institute, Cary, NC, USA). Differences with $\mathrm{p}<0.05$ were considered statistically significant.

\section{Results}

Expression of TDGF1 in clinical tissue specimens and clinicopathological characteristics. We performed quantitative realtime RT-PCR with paired primary and adjacent non-cancerous CRC regions. RT-PCR on 55 paired clinical samples showed that 17 of these cases $(30.9 \%)$ exhibited higher levels of $T D G F 1$ mRNA in tumors than in paired normal tissues. $T D G F 1$ expression was calculated by dividing TDGF 1/ $G A P D H$ expression. For clinicopathological evaluation the experimental samples were divided into 2 groups according to expression status. Patients with values more than the median $T D G F 1$ expression value (median, 1,960) were assigned to the high-expression group and the others were assigned to the lowexpression group. Clinicopathological factors related to the TDGF 1 expression status of the 55 patients are summarized in Table I. The results indicated that TDGF1 expression was correlated with lymphatic invasion $(\mathrm{p}=0.041)$, venous invasion $(\mathrm{p}=0.010)$, and metastasis $(\mathrm{p}=0.052)$. To examine the correlation with metastasis, which indicated a poor prognosis, the data were divided into monochronous and metachronous metastasis groups, and TDGF1 expression was evaluated for 
Table I. Clinicopathological factors and TDGF1 mRNA expression in 55 colorectal cancers.

\begin{tabular}{lccc}
\hline Factors & $\begin{array}{c}\text { High } \\
\text { expression }\end{array}$ & $\begin{array}{c}\text { Low } \\
\text { expression }\end{array}$ & P-value \\
$\mathrm{n}=27(\%)$ & $\mathrm{n}=28(\%)$ &
\end{tabular}

$\begin{array}{llll}\text { Age (years) } & & & \\ \geq 68 & 11(40.7) & 16(57.1) & 0.222 \\ <68 & 16(59.3) & 12(42.9) & \end{array}$

Gender

Male

Female

$$
\begin{array}{ll}
14(51.8) & 17(60.7) \\
13(48.2) & 11(39.3)
\end{array}
$$$$
0.507
$$

Histological grade

Wel/Mod
Others

$$
\begin{array}{rr}
23(85.2) & 25(89.3) \\
4(14.8) & 3(10.7)
\end{array}
$$

Tumor size

$$
\begin{aligned}
& \geq 50 \mathrm{~mm} \\
& <50 \mathrm{~mm}
\end{aligned}
$$

$$
\begin{array}{ll}
10(37.0) & 17(60.7) \\
17(63.0) & 11(39.3)
\end{array}
$$

0.079

Tumor invasion

Tis
T1
T2
$\mathrm{T} 3$
$\mathrm{~T} 4$

Lymph node metastasis

$\begin{array}{lrrr}\text { N0 } & 17(66.7) & 20(71.4) & 0.702 \\ \text { N1-2 } & 9(33.3) & 8(28.6) & \end{array}$

Lymphatic invasion

$\begin{array}{lrr}\text { Absent } & 4(14.8) & 11(39.3) \\ \text { Present } & 23(85.2) & 17(60.7)\end{array}$

$\underline{0.041}$

Venous invasion

$\begin{array}{crrr}\text { Absent } & 11(40.7) & 21(75.0) & \underline{0.010} \\ \text { Present } & 16(59.3) & 7(25.0) & \\ \text { Metastasis } & & & \\ \text { M0 } & 17(63.0) & 24(85.7) & 0.052 \\ \text { M1 } & 10(37.0) & 4(14.3) & \end{array}$

\section{UICC stage}

$\begin{array}{lrrr}0 & 1(3.7) & 6(21.4) & 0.133 \\ \text { I } & 4(14.8) & 8(28.6) & \\ \text { IIA } & 7(25.9) & 5(17.8) \\ \text { IIB } & 2(7.4) & 1(3.6) \\ \text { IIIA } & 1(3.7) & 0(0) \\ \text { IIIB } & 2(7.4) & 2(7.1) \\ \text { IIIC } & 0(0) & 2(7.1) \\ \text { IV } & 10(37.0) & 4(14.3)\end{array}$

Statistically significant values are underlined. Wel, well differentiated adenocarcinoma; Mod, moderately differentiated adenocarcinoma; Others, poorly differentiated adenocarcinoma and mucinous carcinoma.
Table II. Metastasis and TDGF1 mRNA expression in the 55 patients.

\begin{tabular}{lrrr}
\hline Factors & $\begin{array}{c}\text { High } \\
\text { expression } \\
\mathrm{n}=27(\%)\end{array}$ & $\begin{array}{c}\text { Low } \\
\text { expression } \\
\mathrm{n}=28(\%)\end{array}$ & P-value \\
\hline Monochronous metastasis & & & \\
Absent & $24(88.9)$ & $25(89.3)$ & 0.052 \\
Present & $3(11.1)$ & $3(10.7)$ & \\
Metachronous metastasis & & & \\
Absent & $17(70.8)$ & $24(96.0)$ & $\underline{0.017}$ \\
Present & $7(29.2)$ & $1(4.0)$ & \\
\hline
\end{tabular}

Underlined values indicate statistical significance.

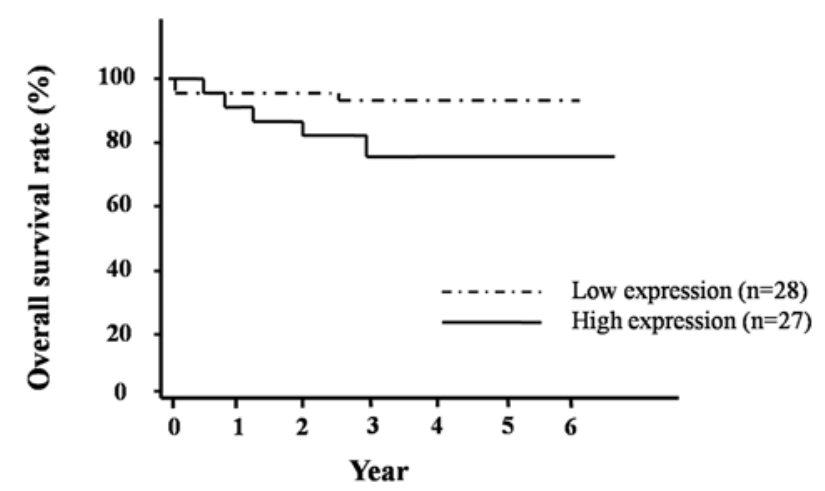

Figure 1. Overall survival rates of colorectal cancer patients based on TDGF1 mRNA expression status. The overall survival rate was lower in the TDGF1 high-expression group than the low-expression group $(\mathrm{p}=0.144)$.

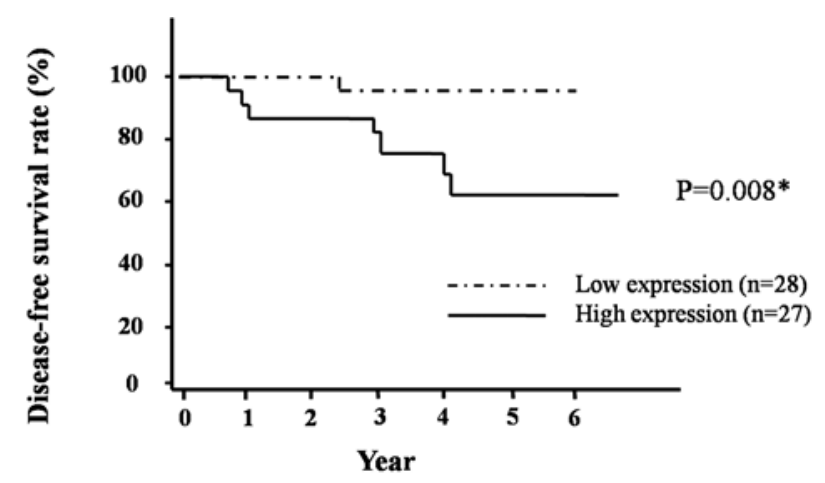

Figure 2. Disease-free survival rates of colorectal cancer patients, exclusive of monochronous metastasis, based on TDGF1 mRNA expression status. The disease-free survival rate was significantly lower in patients whose samples highly expressed TDGF1 mRNA than those with lower expression $(\mathrm{p}=0.008)$.

each factor (summarized in Table II). The results indicated that TDGF1 expression was significantly correlated with metachronous metastasis $(\mathrm{p}=0.017)$.

Relationship between TDGF1 expression and prognosis. Postoperative overall survival was shorter in patients with elevated TDGF 1 expression ( $\mathrm{p}=0.144$ ) than in those with lower expression. The median follow-up was 4.16 years (Fig. 1). We also evaluated disease-free survival based on the relationship between TDGF1 expression and metachronous metastasis after 
Table III. Univariate and multivariate analyses for disease-free survival in 49 patients with curative surgery (Cox proportional hazards regression model).

\begin{tabular}{|c|c|c|c|c|c|c|}
\hline \multirow[t]{2}{*}{ Factors } & \multicolumn{3}{|c|}{ Univariate analysis } & \multicolumn{3}{|c|}{ Multivariate analysis } \\
\hline & $\mathrm{RR}$ & $95 \% \mathrm{CI}$ & P-value & $\mathrm{RR}$ & $95 \% \mathrm{CI}$ & P-value \\
\hline $\begin{array}{c}\text { Age (years) } \\
\leq 68 />68\end{array}$ & 1.84 & $0.45-9.01$ & 0.391 & & & \\
\hline Gender & & & & & & \\
\hline Male/female & 2.17 & $0.62-18.62$ & 0.192 & & & \\
\hline $\begin{array}{l}\text { Histological grade } \\
\text { Por-others/well-mod }\end{array}$ & 713.31 & - & 0.241 & & & \\
\hline $\begin{array}{l}\text { Tumor size (mm) } \\
\geq 50 /<50\end{array}$ & 3.34 & $0.76-22.91$ & 0.110 & & & \\
\hline $\begin{array}{l}\text { Tumor invasion } \\
\text { T3-4/Tis-2 }\end{array}$ & 3.02 & $0.69-20.70$ & 0.145 & & & \\
\hline $\begin{array}{l}\text { Lymph node metastasis } \\
\text { N1-2/N0 }\end{array}$ & 4.21 & $0.99-17.85$ & 0.051 & & & \\
\hline $\begin{array}{l}\text { Lymphatic invasion } \\
\text { Present/absent }\end{array}$ & - & - & $\underline{0.014}$ & - & - & 0.067 \\
\hline $\begin{array}{l}\text { Venous invasion } \\
\text { Present/absent }\end{array}$ & 2.53 & $0.59-10.72$ & 0.196 & & & \\
\hline $\begin{array}{c}\text { TDGF1 mRNA expressic } \\
<\text { Median/ } \geq \text { median }\end{array}$ & 10.42 & $1.84-195.08$ & $\underline{0.005}$ & 7.78 & $1.37-146.02$ & $\underline{0.017}$ \\
\hline
\end{tabular}

Statistically significant values are underlined. RR, relative risk; CI, confidence interval; Wel, well differentiated adenocarcinoma; Mod, moderately differentiated adenocarcinoma; Por, poorly differentiated adenocarcinoma; Others, poorly differentiated adenocarcinoma and mucinous carcinoma.

A

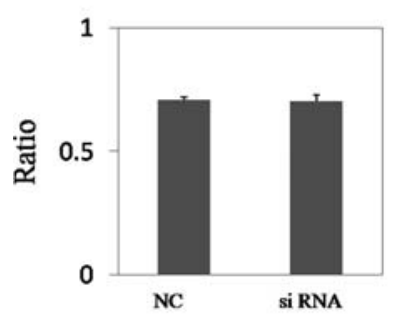

C

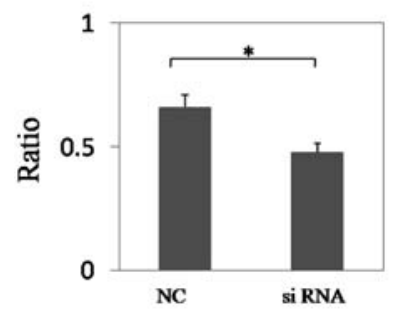

B

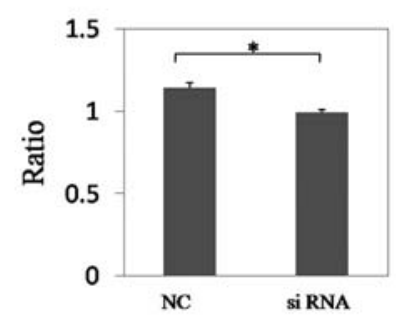

D

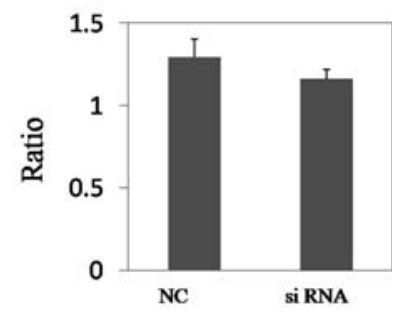

Figure 3. In vitro assays with siRNA inhibition in the two colorectal cancer cell lines. A proliferation assay was performed in two colorectal cancer cell lines (A, HCT116; B, LoVo). There were significant differences between $\mathrm{NC}$ and TDGF1 siRNA in LoVo $\left(\mathrm{n}=5,{ }^{*} \mathrm{p}=0.008\right)$. An invasion assay was performed in them (C, HCT116; D, LoVo). There were significant differences between NC and TDGF1 siRNA in HCT116 ( $\left.\mathrm{n}=5,{ }^{*} \mathrm{p}=0.009\right)$. In vitro assays showed differences in the ratio with control (untreated) cells. Values are means and SEM. NC, negative control.

curative surgery in 49 patients except stage IV at the time of primary operation. The disease-free survival rate was significantly lower in patients with elevated TDGF1 expression $(\mathrm{p}=0.008$; Fig. 2$)$ than in those with lower expression. Table III shows the univariate and multivariate analyses of factors related to metastatic-free survival in 49 patients. The univariate analysis revealed that $T D G F 1$ expression $(\mathrm{p}=0.005)$ and lymphatic invasion (more than maximum repetition, $\mathrm{p}=0.014$ ) were significantly correlated with post-operative metastasis. The multivariate regression analysis indicated that inclusion in the TDGF1 high-expression group (relative risk, 7.78; 95\% confidence interval, 1.37-146.02; $\mathrm{p}=0.017$ ) was an independent predictor of metastatic-free survival.

In vitro assessment of TDGF1 expression knock-down. Two $\mathrm{CRC}$ cell lines were chosen for the proliferation and invasion study. A significant reduction in TDGF1 by siRNA was also confirmed by quantitative real-time RT-PCR. The proliferation study was confirmed by seeding the cells $\left(1.0 \times 10^{5}\right)$ in 6-well dishes and culturing them for $48 \mathrm{~h}$ to determine proliferation. The results showed significant differences in HCT116 and LoVo cell numbers between NC and TDGF 1 siRNA ( $\mathrm{n}=5$, $\mathrm{p}<0.05$, Fig. $3 \mathrm{~A}$ and $\mathrm{B}$ ). In the invasion study, the results showed significant differences in DLD-1 and LoVo between $\mathrm{NC}$ and TDGF 1 siRNA ( $=5, \mathrm{p}<0.05$, Fig. $3 \mathrm{C}$ and $\mathrm{D})$. 


\section{Discussion}

TDGF1, also known as CRYPTO, Crypto-1, or CR-1, is expressed in various cancer tissues of different species (8-16,20-23). Previous in vitro and in vivo reports show that TDGF 1 regulates signaling pathways and cellular mechanisms as an oncogene (23-26). In mammary tumor, TDGF 1 is associated with molecular mechanisms that contribute to the loss of adherent junctions, referred to as epithelialmesenchymal transition, which plays an important role in cancer invasiveness and metastasis and might cause a poor prognosis (25-28). The combined expression of TDGF 1 and E-cadherin by immunohistochemistry indicates a poor prognosis in gastric cancer (16).

The present study showed that TDGF 1 expression is an independent predictive factor for metachronous CRC metastasis, and the siRNA inhibition experiment demonstrated the functional relevance of expressed TDGF1 in the CRC cell lines. To the best of our knowledge, this is the first report to show that TDGF1 is a predictive marker for CRC metastasis, supported by the functional relevance to cell growth and invasion.

It can be useful to identify the necessity for intensive follow-up and adjuvant therapy by predicting CRC recurrence and metastases after curative surgical resection (29-31). Our clinicopathological analysis revealed that CRC patients with high TDGF1 expression had a poorer prognosis for disease-free survival than the low-expression group. The results indicated that $T D G F 1$ is a good predictor for metachronous metastasis, and patients can be followed-up by curative surgical intervention. It is essential to prevent metachronous metastasis during gastrointestinal cancer therapy. Several adjuvant chemotherapies are helpful in particular disease stages, especially in $\mathrm{CRC}$, and indicate the usefulness of a less invasive surgical approach for CRC (31-36). For these cases, a predictive informative marker for tumor recurrence, which is independent from traditional TNM classification and collectively contributes to diagnoses and treatments is very important. While improvement in preoperative and postoperative treatments such as chemotherapy and radiotherapy combined with surgery have contributed to a reduction in the recurrence and metastasis of CRC, half of the cases ultimately metastasize despite systemic chemotherapy followed by surgery (37). Adjuvant chemotherapy for CRC is desirable in highly suspicious metastatic cases. In these cases, an analysis of TDGF 1 may be useful to predict and treat patients with a poor prognosis.

\section{Acknowledgements}

We would like to thank Kimie Kitagawa for the technical assistance.

\section{References}

1. Jemal A, Siegel R, Ward E, et al: Cancer statistics, 2008. CA Cancer J Clin 58: 71-96, 2008.

2. Jones OM, John SK, Horseman N, Lawrance RJ and Fozard JB: Cause and place of death in patients dying with colorectal cancer. Colorectal Dis 9: 253-257, 2007.

3. Kohno SI, Luo C, Nawa A, et al: Oncolytic virotherapy with an HSV amplicon vector expressing granulocyte-macrophage colonystimulating factor using the replication-competent HSV type 1 mutant HF10 as a helper virus. Cancer Gene Ther 14: 918-926, 2007.
4. Yamasaki M, Takemasa I, Komori T, et al: The gene expression profile represents the molecular nature of liver metastasis in colorectal cancer. Int J Oncol 30: 129-138, 2007.

5. Aliaga JC, Deschenes C, Beaulieu JF, Calvo EL and Rivard N: Requirement of the MAP kinase cascade for cell cycle progression and differentiation of human intestinal cells. Am J Physiol 277: G631-G641, 1999.

6. Yamatodani T, Ekblad L, Kjellen E, Johnsson A, Mineta H and Wennerberg J: Epidermal growth factor receptor status and persistent activation of Akt and p44/42 MAPK pathways correlate with the effect of cetuximab in head and neck and colon cancer cell lines. J Cancer Res Clin Oncol 135: 395-402, 2009.

7. Salomon DS, Bianco C and De Santis M: Cripto: a novel epidermal growth factor (EGF)-related peptide in mammary gland development and neoplasia. Bioessays 21: 61-70, 1999.

8. Saeki T, Stromberg K, Qi CF, et al: Differential immunohistochemical detection of amphiregulin and cripto in human normal colon and colorectal tumors. Cancer Res 52: 3467-3473, 1992.

9. Ciardiello F, Kim N, Saeki T, et al: Differential expression of epidermal growth factor-related proteins in human colorectal tumors. Proc Natl Acad Sci USA 88: 7792-7796, 1991.

10. Tsutsumi M, Yasui W, Naito A, et al: Expression of cripto in human pancreatic tumors. Jpn J Cancer Res 85: 118-121, 1994.

11. Friess H, Yamanaka Y, Buchler M, Kobrin MS, Tahara E and Korc M: Cripto, a member of the epidermal growth factor family, is over-expressed in human pancreatic cancer and chronic pancreatitis. Int J Cancer 56: 668-674, 1994.

12. Qi CF, Liscia DS, Normanno N, et al: Expression of transforming growth factor alpha, amphiregulin and cripto- 1 in human breast carcinomas. Br J Cancer 69: 903-910, 1994.

13. Fontanini G, De Laurentiis M, Vignati S, et al: Evaluation of epidermal growth factor-related growth factors and receptors and of neoangiogenesis in completely resected stage I-IIIA nonsmall-cell lung cancer: amphiregulin and microvessel count are independent prognostic indicators of survival. Clin Cancer Res 4: 241-249, 1998

14. D'Antonio A, Losito S, Pignata S, et al: Transforming growth factor alpha, amphiregulin and cripto-1 are frequently expressed in advanced human ovarian carcinomas. Int J Oncol 21: 941-948, 2002.

15. Ertoy D, Ayhan A, Sarac E, Karaagaoglu E, Yasui W and Tahara E: Clinicopathological implication of cripto expression in early stage invasive cervical carcinomas. Eur J Cancer 36: 1002-1007, 2000

16. Zhong XY, Zhang LH, Jia SQ, et al: Positive association of upregulated Cripto-1 and down-regulated E-cadherin with tumour progression and poor prognosis in gastric cancer. Histopathology 52: 560-568, 2008.

17. Sobin LH and Fleming ID: TNM Classification of Malignant Tumors, 5th edition. Union Internationale Contre le Cancer and the American Joint Committee on Cancer. Cancer 80: 1803$1804,1997$.

18. Aznavoorian S, Liotta LA and Kupchik HZ: Characteristics of invasive and noninvasive human colorectal adenocarcinoma cells. J Natl Cancer Inst 82: 1485-1492, 1990.

19. Ishizu K, Sunose N, Yamazaki K, et al: Development and characterization of a model of liver metastasis using human colon cancer HCT-116 cells. Biol Pharm Bull 30: 1779-1783, 2007.

20. Bianco C, Strizzi L, Ebert A, et al: Role of human cripto- 1 in tumor angiogenesis. J Natl Cancer Inst 97: 132-141, 2005.

21. Wechselberger C, Strizzi L, Kenney N, et al: Human Cripto-1 overexpression in the mouse mammary gland results in the development of hyperplasia and adenocarcinoma. Oncogene 24: 4094-4105, 2005.

22. Sun Y, Strizzi L, Raafat A, et al: Overexpression of human Cripto-1 in transgenic mice delays mammary gland development and differentiation and induces mammary tumorigenesis. Am J Pathol 167: 585-597, 2005.

23. Strizzi L, Bianco C, Normanno N, et al: Epithelial mesenchymal transition is a characteristic of hyperplasias and tumors in mammary gland from MMTV-Cripto-1 transgenic mice. J Cell Physiol 201: 266-276, 2004.

24. Ebert AD, Wechselberger C, Nees M, et al: Cripto-1-induced increase in vimentin expression is associated with enhanced migration of human Caski cervical carcinoma cells. Exp Cell Res 257: 223-229, 2000.

25. Savagner P: Leaving the neighborhood: molecular mechanisms involved during epithelial-mesenchymal transition. Bioessays 23 : 912-923, 2001. 
26. Behrens J, Lowrick O, Klein-Hitpass L and Birchmeier W: The E-cadherin promoter: functional analysis of a G.C-rich region and an epithelial cell-specific palindromic regulatory element. Proc Natl Acad Sci USA 88: 11495-11499, 1991.

27. Boyer B, Valles AM and Edme N: Induction and regulation of epithelial-mesenchymal transitions. Biochem Pharmacol 60: 1091-1099, 2000

28. Mani SA, Guo W, Liao MJ, et al: The epithelial-mesenchymal transition generates cells with properties of stem cells. Cell 133: 704-715, 2008.

29. Wolpin BM and Mayer RJ: Systemic treatment of colorectal cancer. Gastroenterology 134: 1296-1310, 2008.

30. Kornmann M, Formentini A, Ette C, et al: Prognostic factors influencing the survival of patients with colon cancer receiving adjuvant 5-FU treatment. Eur J Surg Oncol 34: 1316-1321, 2008.

31. Bathe OF, Dowden S, Sutherland F, et al: Phase II study of neoadjuvant 5-FU + leucovorin + CPT-11 in patients with resectable liver metastases from colorectal adenocarcinoma. BMC Cancer 4: 32, 2004.

32. Andre T, Quinaux E, Louvet C, et al: Phase III study comparing a semimonthly with a monthly regimen of fluorouracil and leucovorin as adjuvant treatment for stage II and III colon cancer patients: final results of GERCOR C96.1. J Clin Oncol 25: 3732-3738, 2007.
33. Lacy AM, Garcia-Valdecasas JC, Delgado S, et al: Laparoscopy-assisted colectomy versus open colectomy for treatment of non-metastatic colon cancer: a randomised trial. Lancet 359: 2224-2229, 2002.

34. Weeks JC, Nelson H, Gelber S, Sargent D and Schroeder G: Short-term quality-of-life outcomes following laparoscopicassisted colectomy vs open colectomy for colon cancer: a randomized trial. JAMA 287: 321-328, 2002.

35. Clinical Outcomes of Surgical Therapy Study Group: A comparison of laparoscopically assisted and open colectomy for colon cancer. N Engl J Med 350: 2050-2059, 2004.

36. Jayne DG, Guillou PJ, Thorpe $\mathrm{H}$, et al: Randomized trial of laparoscopic-assisted resection of colorectal carcinoma: 3-year results of the UK MRC CLASICC Trial Group. J Clin Oncol 25: 3061-3068, 2007

37. Koshariya M, Jagad RB, Kawamoto J, et al: An update and our experience with metastatic liver disease. Hepatogastroenterology 54: 2232-2239, 2007. 